\title{
STRATEGI BLENDED LEARNING FLEX MODEL PADA PEMBELAJARAN ADMINISTRASI JARINGAN KOMPUTER UNTUK MENINGKATKAN PENGALAMAN BELAJAR
}

\author{
Siyamta \\ P4TK BOE / VEDC Malang, \\ Jalan Teluk Mandar, Arjosari, Tromol Pos 5 Malang \\ yamtasiyamta@gmail.com
}

\begin{abstract}
ABSTRAK
Penelitian ini bertujuan untuk mengetahui daya tarik pembelajaran, kemudahan penggunaan feature edmodo untuk pembelajaran serta efektifitas dan efisiensi pembelajaran pada mahasiswa yang menggunakan flex model, dengan mengkombinasikan antara online instruction dan face to face sebagai pelengkap pada pembelajaran administrasi jaringan komputer. Data dikumpulkan dari 30 mahasiswa yang mengikuti pembelajaran administrasi jaringan komputer pada mahasiswa Joint Program VEDC Malang semester 5 tahun 2014. Pembelajaran ini menggunakan blended learning tipe flex model dengan menggunakan Edmodo sebagai social social network (SLN). Untuk mengumpulkan data digunakan skala linkert dengan empat kategori, yaitu sangat setuju (SS) setuju (S), ragu-ragu (R), dan tidak setuju (TS). Berdasarkan data yang diperoleh dari responden, dapat disimpulkan bahwa daya tarik pembelajaran cukup tinggi sebesar $67 \%$ menyatakan sangat setuju dan $33 \%$ setuju. Feature edmodo dapat digunakan secara mudah dengan jawaban responden sebanyak $57 \%$ sangat setuju, $40 \%$ setuju dan $3 \%$ ragu-ragu. Sebanyak $55 \%$ menjawab sangat setuju dan $45 \%$ menyatakan setuju, berkaitan dengan efektifitas dan efisiensi pembelajaran. Hal ini menunjukkan bahwa dengan menggunakan strategi ini akan diperoleh efektitifas dan efisiensi pembelajaran. Temuan ini dapat digunakan sebagai dasar untuk mengembangkan strategi baru dalam pembelajaran yang melibatkan social learning network (SLN) untuk pembelajaran.
\end{abstract}

Kata kunci : flex model, blended learning, social learning network, edmodo, pengalaman belajar

\section{FLEX MODEL BLENDED LEARNING STRATEGY ON COMPUTER NETWORK ADMINISTRATION LEARNING TO IMPROVE LEARNING EXPERIENCE}

\begin{abstract}
This study aims to determine the attractiveness of learning, ease of use features Edmodo for learning as well as the effectiveness and efficiency of learning in students who use flex models, through a combination of online and face-toface instruction as a supplement to learning computer network administration. Data were collected from 30 students who follow the teaching of computer network administration at the Joint Program students VEDC Malang 5th semester of 2014. This study uses flex type of blended learning models using Edmodo as social social network ( SLN ). To collect the data used linkert scale with four categories, namely strongly agree ( SS ) agree ( S), doubtful ( R ), and disagree ( TS ). Based on data obtained from the respondents, it can be concluded that the appeal is quite high learning by $67 \%$ stated strongly agree and $33 \%$ disagree. Edmodo feature can be used easily by as much as $57 \%$ of respondents strongly agree, $40 \%$ disagree and $3 \%$ undecided. A total of $55 \%$ answered strongly agree and $45 \%$ agre, with regard to the effectiveness and efficiency of learning. It is shown that by using this strategy will be obtained efektitifas and learning efficiency. These findings can be used as a basic for developing new strategies for learning that involves social learning network ( SLN ) for learning.
\end{abstract}

Keywords : flex models, blended learning, social learning network, edmodo, experiential learning 


\section{PENDAHULUAN}

Strategi pembelajaran akan berkembang sesuai dengan perkembangan jaman dan teknologi pendukungnya. Mulai abad 21, telah terjadi pergeseran paradigma pembelajaran. Karakteristik beberapa model pembelajaran abad 21 menunjukkan bahwa (1) pembelajaran diarahkan untuk mendorong peserta didik mencari tahu dari berbagai sumber observasi, (2) pembelajaran diarahkan untuk mampu merumuskan masalah, bukan hanya menyelesaikan masalah, (3) pembelajaran diarahkan untuk dapat berfikir analitis, bukan berfikir mekanistis/rutin, (4) pembelajaran menekankan pentingnya kerjasama dan kolaborasi dalam menyelesaikan masalah. Dengan berkembangnya strategi dan model pembelajaran, berkembang pula model pembelajaran yang awalnya bersifat traditional (face to face) ke arah pembelajaran Elektronik (E-Learning). E-learning merupakan model pembelajaran yang menggunakan media elektronik.

Pada kenyataannya, strategi E-Learning tidak dapat menggantikan secara penuh proses belajar mengajar. Beberapa kekurangan $E$ Learning Menurut Bullen (2001) dan Beam (1997) antara lain (1) kurangnya interaksi antara dosen dan mahasiswa atau bahkan antar mahasiswa itu sendiri. Kurangnya interaksi ini bisa memperlambat terbentuknya values dalam proses belajar dan mengajar. Interaksi secara face to face, bahkan harus dilakukan untuk beberapa mata pelajaran tertentu, misalnya praktik memasang instalasi Jaringan Komputer atau bongkar pasang komputer. Oleh karena itu, tidak semua pelajaran dapat dilakukan dengan full e-learning. (2) Kecenderungan mengabaikan aspek sosial. (3) Proses belajar dan mengajarnya cenderung ke arah pelatihan daripada pendidikan. (4) Berubahnya peran dosen atau guru dari yang semula menguasai teknik pembelajaran konvensional, kini juga dituntut mengetahui teknik pembelajaran yang menggunakan TIK. Perubahan peran ini, di satu sisi akan kian memperkuat bagaimana posisi guru atau dosen hanya sekedar fasilitator dan bukan lagi sebagai sumber ilmu. (5) Mahasiswa yang tidak mempunyai motivasi belajar yang tinggi cenderung gagal. Dengan e-learning, mahasiswa yang tidak punya minat terhadap teknologi modern, tidak punya dana untuk memiliki perangkat keras yang memadai, maka ia jelas akan tertinggal oleh rekan-rekannya yang itu berarti ia tengah menuju kegagalan. (6) Tidak semua tempat tersedia fasilitas internet.

Graham CR (2006) mendefinisikan bahwa blended learning merupakan penggabungan dari dua model pembelajaran face to face dan distributed computer mediated serta akan mengalami perkembangan sesuai dengan perkembangan jaman. Dalam blended learning terdapat berbagai kombinasi media, teknologi, aktifitas agar program pelatihan dapat maksimal sesuai dengan karakteristik audience (Bersin, 2004).

Penelitian yang dilakukan oleh Aspden Liz et. al (2004) menunjukkan bahwa strategi blended learning dapat membantu menjembatani jarak antara pebelajar, institusi dengan cara 
interaksi antara pebelajar baik secara online maupun offline serta meningkatkan efektifitas pembelajran dan pengalaman mengajar bagi pembelajar. Komponen dan hubungan di dalam sistem blended learning dikembangkan agar dapat meningkatkan performance pebelajar. Metode yang sesuai di dalam penelitian ini adalah demonstrasi yang dipadukan dalam strategi blended learning (Boyle 2005).

Berdasarkan penelitian dari Ramakrisnan et.al (2012) dijelaskan bahwa Blended Learning merupakan framework yang cocok untuk diterapkan di dunia pendidikan, terutama pendidikan tinggi. Saat ini beberapa perguruan tinggi sedang mencoba untuk menerapkan konsep full e-learning, tetapi sebagian masih terkendala dengan adanya beberapa pebelajar yang masih resistance dengan adanya teknologi yang baru. Hal ini juga sesuai dengan karakteristik dan demografi yang ada di Indonesia, bahwa dengan banyaknya kepulauan serta penyediaan bandwidth yang relatif terbatas, maka model Blended Learning sesuai untuk diterapkan didalam sistem pendidikan di Indonesia.

Blended Learning merupakan suatu kombinasi antara e-learning dan sistem kelas tradisional. Dengan sistem ini maka akan mengakomodasi elemen-elemen dari e-learning contents misalnya simulasi, virtual laboratory, dan online discussions ke dalam pembelajaran tatap muka di kelas. Aktifitas siswa/Siswa dapat ditingkatkan dengan menggunakan blended elearning, termasuk kolaborasi dan diskusi, online quiz dan penugasan, online inquiry dan eksplorasi, seperti aktifitas individual misalnya e-journal, blogs atau e-portfolio. Aktifitas faceto-face dapat juga diterapkan dalam sistem blended e-learning, seperti tutorial, praktikum di laboratorium dan project work. Berdasarkan kajian dari beberapa literatur tentang blended learning, maka strategi ini mempunyai beberapa kelebihan antara lain dilihat dari aspek : (1) peningkatan hasil belajar, (2) efektifitas pembelajaran, (3) kenyamanan belajar, (4) efisiensi biaya, (5) adaptasi gaya belajar yang dimiliki oleh setiap peserta didik.

Pada sistem blended learning berdasarkan Penelitian yang dilakukan oleh Graham (2006), maka tidak ada rumus yang baku untuk menentukan campurannya (blended) dalam konteks pembelajaran. Komposisi blended learning yang umum digunakan adalah 50/50, artinya $50 \%$ digunakan untuk sistem pembelajaran conventional / tatap muka dan 50 $\%$ dilakukan pembelajaran online dan offline. Selain komposisi di atas, ada juga yang menerapkan komposisi $75 / 25$, artinya $75 \%$ pembelajaran tatap muka dan $25 \%$ pembelajaran online. Atau dapat pula dilakukan sebaliknya $25 / 75$, artinya $25 \%$ pembelajaran tatap muka dan 75\% online (Dwiyogo, 2011). Di Indonesia yang masih mengacu pada sistem peraturan akademik, maka pembelajaran konvensional/tatap muka masih dipersyaratkan, sehingga pembelajaran full e-learning belum dapat menggantikan sistem pembelajaran konvensional.

Penelitian yang dilakukan oleh ahli blended learning (Graham, 2006; Dziuban et. al 2004), menunjukkan bahwa strategi blended 
learning telah (a) membantu pebelajar untuk belajar mandiri, (b) menggeser paradigma teacher center menjadi student center, serta (c) pencapaian tujuan pembelajaran. Untuk memperoleh hasil yang optimal dalam strategi blended learning, maka pembelajar harus memiliki pengetahuan tentang strategi pembelajaran sert mengetahui karakteristik pebelajar. Dengan mengetahui karakteristik pebelajar, maka dapat disiapkan materi pembelajaran yang sesuai.

Blended learning akan mengkombinasikan antara traditional learning dan electronic learning dan saat ini berkembang dengan pesat, sehingga memungkinkan untuk : (1) adanya pergeseran paradigma pembelajaran yang awalnya berpusat kepada guru menuju paradigma baru yang berpusat pada siswa/Siswa (student centered learning), (2) adanya peningkatan interaksi antara Siswa dengan atau dosen dengan sumber belajar lainnya, (3) adanya konvergensi antara berbagai media belajar, sumber belajar, lingkungan belajar dan metode belajar yang sesuai. Pada strategi blended learning, hal lain yang perlu diperhatikan adalah learning object, baik online maupun offline. Dengan sistem blended learning ini, maka pebelajar akan lebih banyak berinteraksi dengan learning object tersebut.

Berdasarkan Staker \& Horn (2012), strategi blended learning berkembang dengan munculnya model-model baru, yaitu (1) rotation model, merupakan kombinasi pembelajaran online dengan tatap muka secara rotasi, (2) the flex model, model dengan pengiriman materi dan pembelajarannya melalui internet, tetapi dengan pengawasan pembelajar di dalam kelas, (3) self blend model, dengan pebelajar memilih pembelajarannya secara mendiri, tetapi dilakukan didalam lingkungan pembelajran yang sama, (4) enriched virtual model, dilakukan pengiriman content dan pembelajaran secara online dan dilakukan pertemuan tatap muka ketika diperlukan dan hanya sebagai suplemen. Dari keempat model blended learning tersebut di atas, model 2 dan 4 mendekati dengan karakteristik yang terjadi di perguruan tinggi berdasarkan dengan usia pebelajarnya.

$$
\text { Jaringan sosial merupakan trend }
$$
teknologi terbaru dan menarik untuk dilakukan penelitian. Jaringan sosial pembelajaran seperti Edmodo memungkinkan user untuk dapat berkomunikasi dengan teman-temannya dalam group tertentu. Edmodo merupakan microblogging yang bersifat private yang dapat digunakan oleh dosen, guru dengan mahasiswa atau siswa. Edmodo diperkenalkan pada bulan September 2008 oleh Jeff O’Hara dan Nic Borg.

Pada awalnya edmodo digunakan untuk membantu guru dan siswa dalam hal berkomunikasi dan berkolaborasi menggunakan platform pembelajaran berbasis jaringan sosial. Dengan menggunakan Edmodo dapat dilakukan sharing ide, file, events dan penugasan pada lingkungan virtual.

Beberapa feature yang dimiliki Edmodo antara lain (1) note, berisi tulisan yang nantinya dapat dipublish pada wall edmodo. (2) Allert, berisi suatu peringatan penting yang ditulis guru untuk disampaikan kepada siswa atau group 
tertentu dengan panjang karakter maksimal 140. (3) Assignment digunakan oleh guru untuk memberikan penugasan kepada mahasiswa secara online. Pada feature ini terdapat pengaturan waktu dan button Turn In untuk mengupload tugas dari siswa. (4) File and Links, digunakan untuk mengupload file dan melakukan hyperlink pada website lain. (5) Quiz, digunakan untuk memberikan soal evaluasi secara online yang dilakukan oleh guru. Bentuk quiz yang disediakan Edmodo berupa soal multipple choice, true false, short answer, fill in the blank dan matching. (6) Poolling digunakan untuk melakukan pooling terhadap siswa yang berkaitan dengan proses belajar mengajar. (7) Library, berisi file-file yang diupload oleh guru. Pada sissi siswa, library ini dikenal dengan istilan backpack. (8) Gradebook, berisi catatan nilai dari guru untuk siswa. Pengisian gradebook ini dapat dilakukan secara otomatis maupun manual. Pada soal quiz, rekap penilainnya dilakukan secara otomatis oleh sistem Edmodo. Pada sisi siswa terdapat parent code yang berupa kode yang digunakan oleh orang tua untuk dapat bergabung di kelas Edmodo yang berfungsi sebagai pengawasan kegiatan belajar mengajar dalam kelas virtual.

Daya tarik sebagai hasil pembelajaran, erat sekali berkaitan dengan daya tarik bidang studi. Meskipun demikian, daya tarik bidang studi dalam penyampaiannya akan banyak tergantung pada kualitas pembelajarannya. Pengukuran daya tarik pembelajaran dapat dilakukan denganmengamati apakah siswa ingin terus belajar atau tidak. Dengan demikian kecenderungan siswa untuk tetap terus belajar dapat terjadi karena daya tarik bidang studi itu sendiri maupun kualitas pembelajarannya, termasuk media yang digunakan dan strateginya (Degeng, 2013).

Menurut Degeng (2013), dalam mengukur efisiensi pembelajaran, indikator utamanya berdasarkan pada waktu, personalia dan sumber belajar yang digunakan. Program pembelajaran dirancang sesuai dengan alokasi waktu belajar yang disediakan. Pengukuran efisiensi pembelajaran dilakuka ndengan membandingkan pelaksanaan beberapa program yang berbeda dalam jumlah waktu yang sama, kemudian pencapaian tujuan setiap program tersebut dibandingkan. Pada kegiatan pembelajaran, bagi siswa akan diperoleh pengalaman belajar. Pengalaman belajar dapat diperoleh melalui interaksi antara siswa dengan sesuatu di luar dirinya dan berada dilingkungannya. Dengan kata lain merupakan aktivitas atau kegiatan yang dilakukan oleh siswa selama pembelajaran Administrasi Jaringan Komputer merupakan salah satu mata kuliah wajib pada program studi Teknik Informatika Joint Program VEDC Malang. Materi pada mata kuliah ini berisi tentang bagaimana mahasiswa dapat mengadministrasi server dalam jaringan, antara lain tugas dan tanggungjawab administrator jaringan, DHCP Server, DNS Server, Web Server, FTP Server, NTP Server dan Mail Server. 


\section{METODE PENELITIAN}

Penelitian ini menerapkan strategi blended learning model flex dengan memanfaatkan jaringan sosial pembelajaran Edmodo pada mata kuliah administrasi jaringan komputer. Penelitian ini menggunakan tipe deskriptif untuk mendiskripsikan data yang diperoleh di lapangan. Data kuantitatif diperoleh menggunakan skala linkert yang dimulai dari Sangat Setuju (1/SS), Setuju (2/S), Ragu-Ragu ( 3/R ) dan Tidak Setuju (4/TS). Untuk meningkatkan pengalaman belajar, digunakan social learning network (SLN) Edmodo. Materi disediakan dalam bentuk slide Power Point, FlipBook, Online Quizz, Video dan Hyperlinks. Pada pertemuan pertama dilakukan secara face to face, kemudian pembelajaran blended diperkenalkan kepada mahasiswa. Semua materi perkuliahan diupload di dalam Edmodo dengan membentuk group kelas virtual. Dengan terbentuknya group kelas virtual, maka akan digenerate kode group yang nantinya digunakan sebagai login dari peserta yang akan bergabung di dalam kelas virtual. Penugasan dan hasiil praktikum diupload di dalam kelas virtual dengan waktu yang dapat ditentukan oleh dosen.

Instrument penelitian yang digunakan diadopsi dari survey yang dikembangkan oleh Owston dan York (2012) dengan beberapa modifikasi agar sesuai dengan kriteria yang diinginkan. Penelitian ini dilakukan pada Joint Program VEDC Malang dengan jumlah 30 Mahasiswa Program Studi Teknik Informatika semester 5 .

\section{HASIL DAN PEMBAHAS-AN}

Hasil penelitian ini mendeskripsikan tentang (1) daya tarik strategi blended learning dalam kegiatan pembelajaran, (2) kemudahan feature edmodo untuk pembelajaran (3) effektifitas dan effisiensi pembelajaran. Halaman utama edmodo pada salah satu kelas virtual ditunjukkan seperti gambar 1 berikut ini.

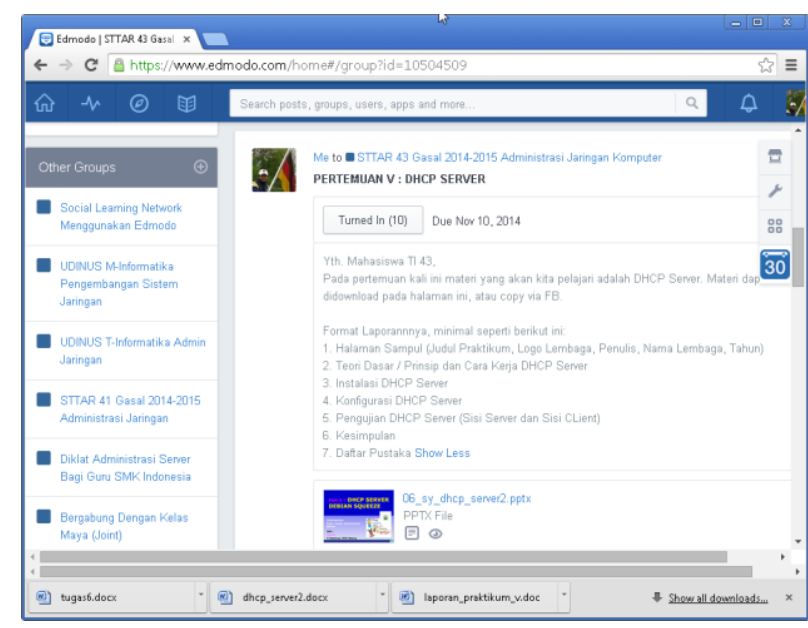

Gambar 1. Halaman utama salah satu kelas virtual pada Edmodo

Pada gambar di atas ditunjukkan salah satu halaman utama kelas virtual pada pembelajaran Administrasi Jaringan Komputer. Pada halaman tersebut diberikan assignment oleh dosen kepada mahasiswanya untuk mempelajari materi tentang DHCP Server, kemudian melakukan praktikum serta membuat laporan praktikum untuk diupload pada halaman yang sama. Setelah mahasiswa mengupload tugas yang diberikan oleh dosen, maka pada halaman dosen akan tampil semua mahasiswa yang telah tergabung beserta status pengumpulan tugasnya. Contoh status pengumpulan tugas, ditunjukkan pada gambar 2 berikut ini. 


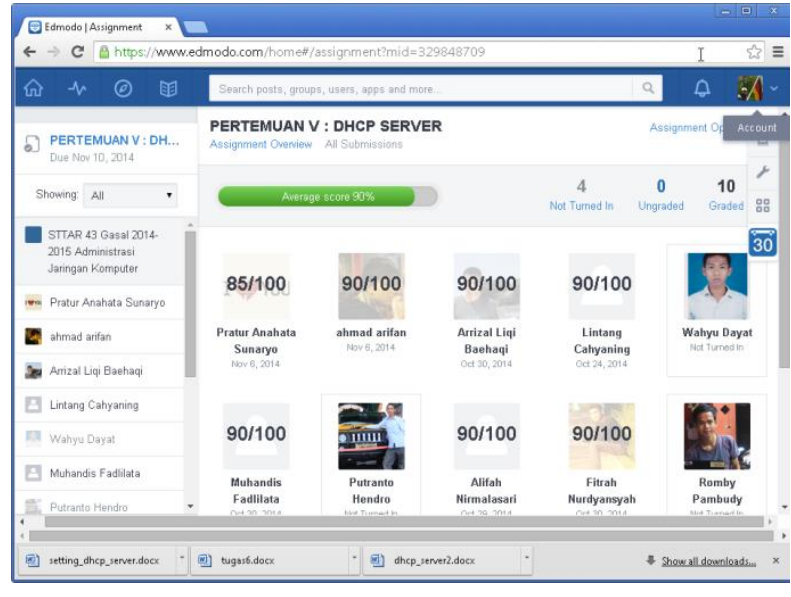

Gambar 2. Halaman all submissions kelas virtual pada Edmodo

Pada Gambar 2 di atas, terlihat bahwa ada mahasiswa yang mengumpulkan laporan praktikum tanggal 30 Oktober 2014, ada juga yang mengumpulkan tanggal 6 November 2014 bahkan ada yang belum melakukan Turn In. Penilaian dapat dilakukan secara otomatis oleh sistem atau dilakukan secara manual oleh dosen yang mengelola kelas virtual tersebut. Jika mahasiswa tidak mengumpulkan praktikumnya pada waktu yang telah ditentukan, maka tidak akan dapat mengumpulkan tugasnya, kecuali dilakukan konfigurasi ulang oleh dosennya.

Berdasarkan kuestioner yang diperoleh dari responden, maka diperoleh data sebagai berikut ini. Sebanyak $67 \%$ menyatakan bahwa responden tertarik atau sangat setuju dengan strategi pembelajaran yang mengkombinasikan face to face di kelas yang dikombinasikan dengan online menggunakan edmodo, serta $33 \%$ menyatakan sangat setuju. Dengan demikian strategi ini cocok diterapkan dalam pembelajaran administrasi jaringan komputer di Joint Program VEDC Malang.

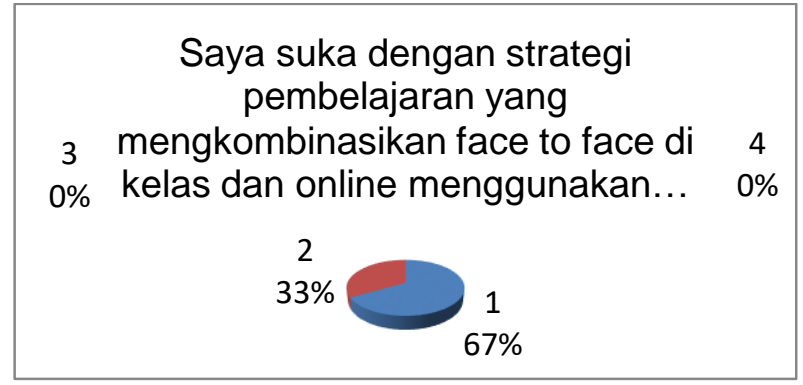

Gambar 3. Prosentase penggunaan strategi pembelajaran

Berkaitan dengan kemudahan feature pada edmodo, sebanyak $57 \%$ responden menjawab sangat setuju $40 \%$ menjawab setuju dan $3 \%$ menjawab ragu-ragu. Hal ini dapat disimpulkan bahwa feature edmodo mudah digunakan untuk mendukung kegiatan pembelajaran.

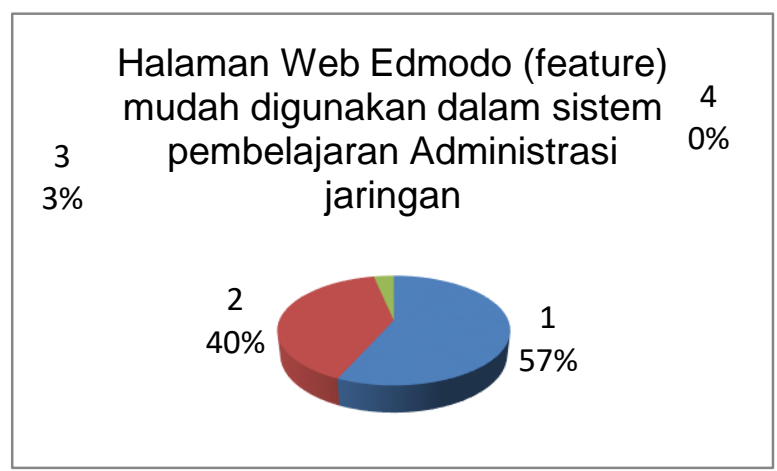

Gambar 4. Kemudahan feature pada Edmodo

Berkaitan dengan efektifitas dan efisiensi pembelajaran, sebanyak $55 \%$ responden menyatakan bahwa sangat setuju dan $45 \%$ menyatakan setuju. Hal ini menunjukkan bahwa sebagian besar mahasiswa menyatakan bahnya dengan menggunakan strategi blended leraning akan lebih efektif dan efisien dalam kegiatan belajar mengajar. 


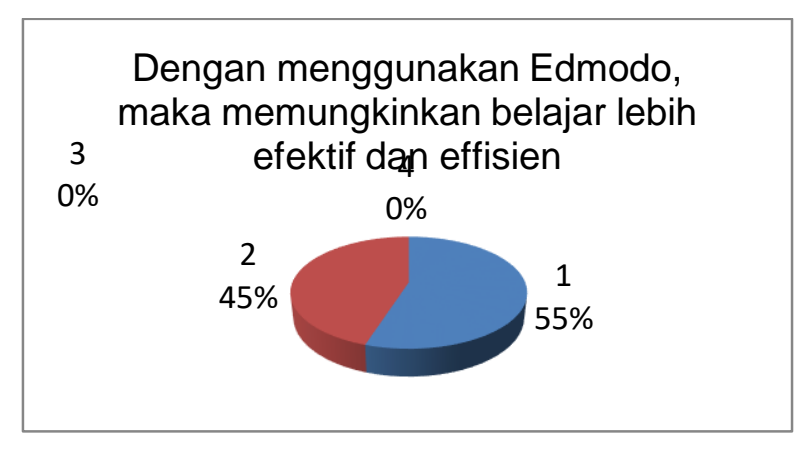

Gambar 5. Efektifitas dan efisiensi pembelajaran menurut responden

\section{KESIMPULAN}

Berdasarkan hasil penelitian dan pembahasan di atas dapat disimpulkan bahwa :

- Daya tarik pembelajaran dengan strategi blended learning, tergolong tinggi dengan jawaban responden sebanyak $67 \%$ menyatakan sangat setuju dan $33 \%$ menyatakan setuju.

- Feature edmodo untuk pembelajaran tergolong mudah dengan jawaban responden sebanyak $57 \%$ menyatakan sangat setuju, $40 \%$ menyatakan setuju dan $3 \%$ menyatakan ragu-ragu.

- Efektifitas dan efisiensi pembelajaran dengan menggunakan strategi blended learning ini termasuk tinggi dengan $55 \%$ menyatakan sangat setuju dan $45 \%$ menyatakan setuju.

Berdasarkan kesimpulan di atas, disarankan agar guru atau dosen selalu mengikuti perkembangan teknologi pembelajarannya, terutama dengan memanfaatkan teknologi informasi (TI), agar tidak monoton serta dapat ditinggalkan oleh siswa atau mahasiswanya.

\section{DAFTAR PUSTAKA}

Aspden, Liz; Helm Paul (2004). Making The Connection in Blended Learning Environment, Educational Media International, Vol 42, Page 245-252.

Beam.P.1997. Breaking The Sprinter's Wrist : Achieving Cost-Effectiveness Online Learning. The International Symposium on Distance Education and Open Learning. Bali. Indonesia : MONE Indonesia, IDLN.SEAMOLEC.ICDE. UNDP dan UNESCO.

Bersin, J. 2004. The Blended Learning Book: Best Practice, Proven Methodologies and Lessons Learned. New York: John Wiley \& Sons Inc.

Boyle, Tom, 2005. A Dynamic Systematic Method for Developing Blended Learning, Education, Communication and Information Journal, Vol 5, Page 221 - 232.

Bullen, M. 2001. E-learning and the Internationalizat Education. Malaysian Journal of Education Technologi. Vol 1. No.1 P.37-46.

Cruz M.B. and Cruz S.B. 2013, The Use od Internet-Based Social Media as a Tool in Enhancing Student's Learning Experiences in Biological Sciences, Higher Learning Research Communications, Volume 3, Number 4.

Degeng Nyoman S (2013), Ilmu Pembelajaran Klasifikasi Variabel untuk Pengembangan Teori dan Penelitian, Bandung : Kalam Hidup.

Dziuban CD et. al (2004) Research Bulletin Blendel Learning, Volume 7, 30 March 2004, Uducase.

Dwiyogo, W.D. 2011. Pembelajaran Berbasis Blended Learning, Sinergi Antara Pembelajaran Tatap Muka, Offline dan Online. Prosiding Seminar Internasional. Jurusan Teknologi Pendidikan Universitas Negeri Malang 27-28 Juli 2011.

Graham CR. 2006. Intoductions to Blended Learning, http://media.wiley.com/ product data/excerpt/86/07879775/0 787977586.pdf. Diakses Tanggal 18 September 2014, jam 16:54 WIB. 
Graham CR. 2006. Blended Learning Systems : Definition, Current Trends and Future Directions, dalam C. Bonk and C. Graham (Eds), The Hand Book of Blended Learning, Global Perspectives Local Design. San Francisco : John Wiley \& Sons, Inc., Halaman 3 -19.

Owston, R \& York, D (2012). Evaluation of blended learning course in the faculty of Liberal Arts and Professional Studies and the Faculty of Health-Winter Session 2012 (Technical Report No 2012-3). Toronto : Institut for Research on Learning Technologies.
Ramakrisnan P et.al (2011). Blended Learning: A Suitable Framework For E-Learning In Higher Education, The $3^{\text {rd }}$ International Conference On e-Learning, Procedia Computer Science 67 (2012) page 513-526.

Staker H and Horn Michael B. 2012. Cassifying K-12 Blended Learning, http://www. innosightinstitute.org. 